\title{
Clinical audit of health promotion of vitamin D in one general practice
}

Marjan Kljakovic ${ }^{1 *}$, Cathy Davey ${ }^{2}$, Rashmi Sharma ${ }^{3}$ and Divya Sharma ${ }^{4}$

\begin{abstract}
Background: The clinical audit of vitamin $D$ health promotion in one Australian general practice was undertaken by measuring health service use and serum 25-hydroxyvitamin D levels in 995 patients aged 45 to 49 years.

Findings: Over 3 years, 486 (51\%) patients had a Medicare funded Health Assessment. More women (54\%) were assessed than men (46\%) $\mathrm{p}=0.010$. Mean $25-\mathrm{OHD}$ was higher for men $(70.0 \mathrm{nmol} / \mathrm{l})$ than women $(60.3 \mathrm{nmol} / \mathrm{l}) \mathrm{p}$ $<0.001$. More patients had their weight measured (50\%) than $25-\mathrm{OHD}$ tested (28\%).

Among 266 patients who had a 25-OHD test, 68 (26\%) had normal levels 80+ nmol/l, 109 (41\%) were borderline $51-79 \mathrm{nmol} / \mathrm{l}$, and 89 (33\%) were low $<51 \mathrm{nmol} / \mathrm{l}$. Mean $25-\mathrm{OHD}$ was higher in summer $(73.7 \mathrm{nmol} / \mathrm{l})$ than winter $(54.7 \mathrm{nmol} / \mathrm{l}) \mathrm{p}<0.001$. Sending uninvited written information about $25-\mathrm{OHD}$ had no effect on patients' subsequent attendance.
\end{abstract}

Conclusions: Health promotion information about vitamin D was provided to $50 \%$ of a targeted group of patients over a one-year period. Provision of this information had no effect on the uptake rates of an invitation to attend for a general health assessment.

Keywords: Vitamin D, Health promotion, General practice, Clinical audit

\section{Findings}

The RACGP (Royal Australian College of General Practitioner) Red Book provides specific recommendations on vitamin $\mathrm{D}$ and sunlight exposure in health promotion[1]. This clinical audit was initiated when one GP (general practitioner) at the IPMC (Isabella Plains Medical Centre) observed that many patients appeared to be deficient in serum vitamin $\mathrm{D}$. The aim of this clinical audit was to evaluate how IPMC managed its health promotion surrounding vitamin D.

\section{Method}

Practice setting

IPMC has 10 full-time equivalent GPs, four practice nurses, and five allied health workers who care for a practice population of 19,417 patients. The audit occurred in two parts over a three-year period between November 2006 and December 2009. The selection

\footnotetext{
* Correspondence: Marjan.kljakovic@anu.edu.au

${ }^{1}$ Academic Unit of General Practice in the School of General Practice, Rural and Indigenous Health, at the Australian National University Medical School, PO Box 11 Woden, ACT 2606 Canberra, Australia

Full list of author information is available at the end of the article
}

criteria included all patients registered with IPMC electronic health records and eligible for a Health Assessment funded through Medicare Item Number 717 (A policy introduced by the commonwealth government on 1st November 2006 meant for patients aged 45 to 49 years to consult for reasons of health promotion in general practice).

\section{Part 1 Audit}

described the characteristics of patients aged 45-49 years who consulted the practice under Item Number 717 between November 2006 and October 2008.

\section{Part 2 Audit}

measured the impact of written advice on patients who consulted IPMC for health promotion between October 2008 and December 2009. Patients were sent a letter inviting them to consult with IPMC. Half were randomly selected to receive the invitation only, the other half received the invitation letter as well as specific information contained in a Cancer cosmetics pamphlet [2] on the role of vitamin D and how to obtain a blood test.

\section{Ciomed Central}


The variables measured in this audit were the number of people who attended IPMC under Item Number 717 and their serum 25-OHD (25-hydroxyvitamin D) levels, the serum biomarker of vitamin D. Patients who are subsequently found to have a low 25-OHD level are routinely retested at six months intervals. The local laboratory determined the normal range for 25-OHD was $51 \mathrm{nmol} / \mathrm{l}$ to $140 \mathrm{nmol} / \mathrm{l}$ : A low level was defined as < $51 \mathrm{nmol} / 1$ 25-OHD, 51-79 nmol/1 was defined borderline, and $80+\mathrm{nmol} / \mathrm{l}$ was defined normal. The season in which the test was taken was also measured). Other variables included gender, weight, BMI, waist circumference, and the level of activity patients reported they performed in daily life. (Ranked on a 14-point Likert scale where 0 -points was no daily physical activity to 14points was 60 minutes of activity daily at a very strenuous level).

Data were coded in excel and analysed in PASW Statistics $18^{\mathrm{TM}}$ comparing differences between categories using the non-parametric chi squared test where appropriate.

Ethical approval was not sought for this audit because it met the National Health and Medical Research Council's criteria for exemption [3], namely the audit was undertaken with the consent of IPMC and patients were unlikely to suffer any burden or harm. Only anonymous data were collected for this audit and stored at the general practice.

\section{Results}

\section{Part 1 of Audit}

Of 955 patients audited, 486 (51\%) had a Medicare funded Health Assessment and significantly more women (54\%) had this assessment than men (46\%) (316 women versus 170 men, Pearson Chi-Square $=6.57, \mathrm{df}$ $=1, \mathrm{p}=0.010)$. Among the $469(49 \%)$ patients who did not have a Medicare funded Health Assessment, significantly more men (54\%) did not have this assessment than women (46\%) (202 men versus 267 women, Pearson Chi-Square $=6.57$, df $=1, \mathrm{p}=0.010)$.
There were 474 patients (50\%) who had their weight measured; 473 (50\%) had their BMI score calculated; 427 (45\%) had their waist measured; 432 (45\%) had their activity score measured; And 266 (28\%) had a 25OHD test. Table 1 shows males were significantly heavier and had larger waists than women, but no difference in BMI or activity scores than women. Women had significantly lower 25-OHD than men, even though more women had a 25-OHD test taken than men $(32 \%$ versus 21\%, Pearson Chi-Square $=13.28$, df $=1, \mathrm{p}<$ 0.001).

Among 486 patients who had a Health Assessment, 220 patients $(45 \%)$ did not have a 25 -OHD test, 207 patients (43\%) had one test, 46 patients $(9.5 \%)$ had two 25-OHD tests, and 13 patients (3\%) had three 25-OHD tests.

Among the 266 patients who had 25-OHD tests, 89 patients (33\%) had low 25-OHD of < $51 \mathrm{nmol} / \mathrm{l}, 109$ patients (41\%) had borderline 25-OHD of 51-79 nmol/l, and 68 patients $(26 \%)$ had normal 25-OHD of $80+$ nmol/l. Table 2 shows that 59 patients (66\%) had a follow up 25-OHD test six months later. Among the 56 patients who had low 25-OHD at initial assessment, 19 patients (34\%) remained at a low level at follow up, 32 patients $(57 \%)$ changed to borderline, and 5 patients (9\%) changed to normal.

Table 3 shows a seasonal variation of when the 25OHD tests were taken in 266 patients with $34 \%$ taken in autumn, $14 \%$ in winter, $20 \%$ in spring, and $31 \%$ in summer. The variation among the 89 patients who had low 25 -OHD differed with $31 \%$ taken in autumn, $22 \%$ in winter, $33 \%$ in spring, and $13 \%$ in summer.

\section{Part 2 of Audit}

Of the 584 patients who were sent general health advice in the mail, $50 \%$ were randomly selected to receive additional written information about vitamin D, and $50 \%$ were not. Part 2 Audit resulted in an additional 115 patients having a Health Assessment (20\% of total). There was no difference in the proportion of patients

Table 1 Gender comparison of weight, waist, BMI, Activity score, and serum 25-hydroxyvitamin D (25-OHD) levels in 955 patients aged 45 to 49 years in one general practice in Canberra

\begin{tabular}{|c|c|c|c|c|c|c|c|c|c|c|}
\hline \multirow[t]{2}{*}{ Variable } & \multicolumn{4}{|l|}{ Male } & \multicolumn{4}{|l|}{ Female } & \multirow[t]{2}{*}{$t$ test } & \multirow[t]{2}{*}{$P$ value } \\
\hline & Minimum & Maximum & Mean & SD & Minimum & Maximum & Mean & SD & & \\
\hline Weight (Kilograms) & 55 & 125 & 90.0 & 14.2 & 47 & 143 & 78.34 & 17.8 & 8.5 & 0.000 \\
\hline Waist (centimetres) & 72 & 136 & 96.9 & 12.6 & 26 & 127 & 86.88 & 14.2 & 8.3 & 0.000 \\
\hline $\mathrm{BMI}^{*}$ score & 20 & 43 & 27.4 & 4.4 & 21 & 53 & 28.08 & 6.7 & 0.1 & 0.471 \\
\hline Activity score & 0 & 8 & 3.9 & 2.0 & 0 & 10 & 3.09 & 2.2 & - & $0.500^{*}$ \\
\hline 25-OHD level (nmol/l) & 10 & 141 & 74.0 & 28.8 & 12 & 228 & 60.3 & 26.3 & 3.8 & 0.000 \\
\hline
\end{tabular}

$\mathrm{BMI}=$ Body mas index $\left(\mathrm{kg} / \mathrm{m}^{2}\right)$ Reference range $\mathrm{BMI}$ of $\geq 25$ conveys increased risk [1]

Waist reference range $\geq 94 \mathrm{~cm}$ in males and $\geq 80 \mathrm{~cm}$ in females conveys increased risk [1]

* Mann-Whitney $U$ test 
Table 2 The number of patients who had initial and six-month follow-up serum 25-hydroxyvitamin D (25-OHD) taken as part of their Health Assessment in general practice $\boldsymbol{n}=\mathbf{2 6 6}$ patients

\begin{tabular}{llllllll}
\hline Number of patients with initial 25-OHD levels* & $\%$ & \multicolumn{4}{l}{ Follow up 25-OHD levels at six months } & Total followed & \% \\
\cline { 5 - 6 } & & & Low & Borderline & Normal & 5 & 56 \\
Low & 89 & $33.5 \%$ & 19 & 32 & 1 & $3 \%$ \\
Borderline & 109 & $41 \%$ & 1 & 1 & - & 0 & $3 \%$ \\
Normal & 68 & $26 \%$ & - & - & $0 \%$ \\
\hline
\end{tabular}

*Low 25-hydroxyvitamin $\mathrm{D}=<51 \mathrm{nmol} / \mathrm{l}$, Borderline 25-hydroxyvitamin $\mathrm{D}=51-79 \mathrm{nmol} / \mathrm{l}$, Normal 25-hydroxyvitamin $\mathrm{D}=80+\mathrm{nmol} / \mathrm{l}$

who had a Health Assessment and received specific written information about vitamin D compared to those who did not $(21 \%$ versus $18 \%$, Pearson Chi-Square = $0.592, \mathrm{df}=1, \mathrm{p}=0.442)$.

\section{Discussion}

This audit revealed that after three years of work IPMC had attempted a Health Assessment of the vitamin D status in $51 \%$ of patients aged 45 to 49 years. Although half of these patients had their weight measured, only $28 \%$ had a test to measure 25-OHD.

The audit revealed a bias towards testing patients who had low or borderline 25-OHD. This suggests that the 25-OHD test was not used as a screening tool; rather it was used for case finding. Knowledge of a patient's low 25-OHD appeared to have little impact on changing the patient's level. Only $8 \%$ of such patients were subsequently shown to revert back to normal levels.

The overall mean 25-OHD level $(74.0 \mathrm{nmol} / \mathrm{l})$ found in this audit was similar to the $76.9 \mathrm{nmol} / \mathrm{l}$ mean level found in a group of Adelaide residents [4] and higher than the $56.8 \mathrm{nmol} / \mathrm{l}$ mean level found in a recent study of adult Aboriginal Australians[5]. Furthermore, the audit confirmed the known seasonal variation in 25OHD [5] by finding a high proportion of 25-OHD tests taken in summer compared to other seasons and a comparatively low proportion of patients with low levels of 25-OHD in summer. In our audit, we did not measure the amount of time patients spent outside. Therefore we can only speculate that the paradoxical relationship between a high proportion of testing undertaken in summer and a low proportion of patients with low levels of 25-OHD in summer is a consequence of patient behaviour - perhaps patients spend less time outside in response to high temperatures in the $\mathrm{ACT}$ in the summer months.

The audit revealed a gender imbalance: Women were more likely to have a health assessment than men and consequently were more likely to have a test. However, women were also found to have significantly lower 25OHD level than men. Furthermore, men were significantly heavier and had larger waists than women, but no difference in BMI or activity scores. These differences suggest that men and women need different practice policies for health promotion.

The audit demonstrated that sending uninvited health promotion information to patients had no effect on subsequent attendance for health promotion in this practice. New health promotion strategies are needed. For example, sending a newsletter to the whole practice population, or working in conjunction with the local media, might stimulate more people to consider the relationship between vitamin $\mathrm{D}$ and the amount of sunlight exposure they experience. The RACGP guidelines for preventive activities in general practice list the strategies that Australian general practice might undertake for health promotion and mentions vitamin $\mathrm{D}$ [1]. The guidelines do not mention how practices might vary their strategies in response to specific characteristics such as the gender profile of the general practice.

The limitations of this clinical audit include the bias of using only one general practice, the non-random selection of patients, the local laboratory determined the normal serum 25-OHD reference range, and the measurement error inherent in undertaking an audit. (In Australian general practice patients may go elsewhere to manage their low 25-OHD and there are limited mechanisms to ensure patients comply on follow up of

Table 3 Seasonal variation of serum 25-hydroxyvitaminin D (25-OHD) in 266 patients from one general practice in Canberra

\begin{tabular}{|c|c|c|c|c|c|}
\hline \multirow[b]{2}{*}{ Season } & \multirow[b]{2}{*}{$n$} & \multirow[b]{2}{*}{$\begin{array}{l}\text { Mean 25-OHD } \\
\text { level (nmol/l) }\end{array}$} & \multicolumn{3}{|l|}{ Number } \\
\hline & & & $<51 \mathrm{nmol} / \mathrm{l}$ & $51-79 \mathrm{nmol} / \mathrm{l}$ & $80+\mathrm{nmol} / \mathrm{l}$ \\
\hline Autumn & 91 & 66.1 & 28 & 42 & 21 \\
\hline Winter & 38 & 54.7 & 20 & 11 & 7 \\
\hline Spring & 54 & 53.8 & 29 & 18 & 7 \\
\hline Summer & 83 & 73.7 & 12 & 38 & 33 \\
\hline
\end{tabular}


low-test results). Finally we did not measure the amount of sunlight exposure in patients.

In summary, a considerable amount of work was undertaken by IPMC over three years resulting in half the target group of patients receiving health promotion, just over a quarter had the appropriate blood test, and none were influenced by uninvited written health information on vitamin $\mathrm{D}$. The audit taught IPMC that men and women need different policies for health promotion on the association between 25-OHD levels and time spent outside in summer.

\section{Authorship}

MK conceived of the study, participated in its design and statistical analysis, and helped to draft the manuscript. CD coordinated with IPMC and collected all data. RS and DS supervised CD and helped with coordinating with IPMC. All authors read and approved the final manuscript.

\section{Abbreviations}

GP: general practitioner; IPMC: Isabella Plains Medical Centre; 25-OHD: 25hydroxyvitamin D; RACGP: Royal Australian College of General Practitioners.

\section{Acknowledgements}

The authors would like to thank the Isabella Plains Medical Centre for giving consent to undertake this clinical audit.

\section{Author details}

'Academic Unit of General Practice in the School of General Practice, Rural and Indigenous Health, at the Australian National University Medical School, PO Box 11 Woden, ACT 2606 Canberra, Australia. ${ }^{2}$ Practice nurse at Isabella Plains Medical Centre, 9 Arakoon Crescent Isabella Plains, ACT 2905 Canberra, Australia. ${ }^{3}$ General practitioner at Isabella Plains Medical Centre, 9 Arakoon Crescent, Isabella Plains, ACT 2905 Canberra, Australia. ${ }^{4}$ General practitioner at Isabella Plains Medical Centre, 9 Arakoon Crescent, Isabella Plains, ACT 2905 Canberra, Australia.

\section{Competing interests}

The authors declare that they have no competing interests.

Received: 19 January 2012 Accepted: 2 April 2012

Published: 2 April 2012

\section{References}

1. The Royal Australian College of General Practitioners: Guidelines for preventive activities in general practice (7th Edition) Melbourne: The Royal Australian College of General Practitioners; 2009.

2. Cancer Council: Vitamin D and sun exposure Cancer Council Australia: Sydney; 2008.

3. National Health and Medical Research Council: National Statement on Ethical Conduct in Human Research Commonwealth of Australia: Canberra; 2007.

4. Morris HA, Morrison GW, Burr M, Thomas DW, Nordin BE: Vitamin D and femoral neck fractures in elderly South Australian women. Med J Aust 1984, 140(9):519-21.

5. Vanlint SJ, Morris HA, Newbury JW, Crockett AJ: Vitamin D insufficiency in Aboriginal Australians. Med J Aust 2011, 194(3):131-4.

doi:10.1186/1447-056X-11-3

Cite this article as: Kljakovic et al: Clinical audit of health promotion of vitamin D in one general practice. Asia Pacific Family Medicine 2012 11:3.

\section{Submit your next manuscript to BioMed Central and take full advantage of:}

- Convenient online submission

- Thorough peer review

- No space constraints or color figure charges

- Immediate publication on acceptance

- Inclusion in PubMed, CAS, Scopus and Google Scholar

- Research which is freely available for redistribution 